\title{
Questions that Have Arisen since the EU Decision on the Whatsapp Acquisition by Facebook*
}

\author{
Vicente Bagnoli*
}

\begin{abstract}
On October $3^{\text {rd }}$, 2014, the European Commission (EC) concluded the analysis of the transaction by which Facebook, Inc. ("Facebook", USA) had acquired WhatsApp Inc. ("WhatsApp", USA) by way of a purchase of shares for US\$ 19 billion, which contributed to Facebook's strategy of focusing its business on mobile development (Case no. COMP/M.7217). In its decision, the EC stated that the deal would raise no competition concerns and authorised the proposed acquisition of WhatsApp by Facebook concluding that Facebook Messenger and WhatsApp are not close competitors and that consumers would continue to have a wide choice of alternatives for consumer communication apps after the acquisition. The EC analysed potential data concentration issues only within the scope that the acquisition could weigh down competition in the online advertising market. Privacy-related concerns from the increased concentration of data within the control of Facebook because of the deal with WhatsApp are not an EU Competition Law matter. Notwithstanding, just some months after the decision two national competition authorities (Germany and Italy) opened procedures against Facebook. In Germany, the Bundeskartellamt initiated in March 2016 a proceeding against Facebook - Facebook Inc., USA, the Irish subsidiary of the company, and Facebook Germany GmbH, Hamburg - on suspicion that
\end{abstract}

\footnotetext{
* Date of Reception: 30 December 2018. Date of Acceptance: 31 January 2019.

** Professor of Law at Mackenzie University; PhD in Philosophy and General Theory of Law at Sao Paulo University - Law School; visiting researcher for Post Doc at Max Planck Institute for Innovation and Competition; Master in Economic and Political Law at Mackenzie University - Law School; member of ASCOLA; member of the scientific committee of the Observatory on Competition Law Enforcement - Portuguese Catholic University of Porto; nongovernmental advisor of ICN; World Bank Group and WIPO Short Term Consultant; member of ICC; Counsellor of IBRAC; President of the Antitrust Section of the Brazilian Bar Association, Sao Paulo (2013-2015); President of the Law Committee of the Italian Chamber of Commerce of Sao Paulo - Italcam; founder-partner of Vicente Bagnoli Law Office; bagnoli@vicentebagnoli.com.br.
} 
Facebook had abused its market power by infringing data protection rules with its specific terms of service on the use of user data. In Italy, in May 2017, the Autorità Garante della Concorrenza e del Mercato (AGCM) fined WhatsApp EUR 3 million for having forced its users to share their personal data with Facebook as a conclusion of two investigations opened in October 2016 concerning infringements of the Consumer Code. The present article proposes to answer three main questions concerning the EC decision on the WhatsApp acquisition by Facebook: (i) Did the EC apply the best tools to analyse the case?; (ii) Could the EC have addressed a decision that would somehow interfere in the privacy field?; and (iii) Could the procedures in Germany and Italy have been avoided?

KEYWORDS: Facebook; WhatsApp; Big Data; Competition Law; Privacy; Data Protection.

\section{Introduction}

Competing in or for the markets, companies are making acquisitions to increase their product or service lines and acquiring new technologies or assets to boost their market power or simply to restrict competition from potential competitors who in any way pose a threat to their business.

In the Digital Economy, ${ }^{1}$ where competition in digital markets has its own characteristics, including trends such as "winner takes all", network effects, two-sided markets, multi-sided markets, platforms, ${ }^{2}$ fast-paced innovation and high sums of investment, data represents an important asset to any company for dealing with a variety of data and in diverse forms. An enormous set of digital data ${ }^{3}$ held by companies, governments and organizations which analyses extensively through algorithms $s^{4}$ is known as Big Data.

If applied in the correct technologies, Big Data can anticipate and solve business problems by knowing consumers better and foreseeing

\footnotetext{
${ }^{1}$ OECD, The Digital Economy, 2012, 5.

2 J. S. Frank, Competition Concerns in Multi-Sided Markets in Mobile Communication. In G. Surblyté, Competition on the Internet. MPI Studies on Intellectual Property and Competition Law, vol. 23 (Berlin: Springer, 2015), 85.

${ }^{3}$ OECD (2015), Data-Driven Innovation: Big Data for Growth and Well-Being, OECD Publishing, Paris. http://dx.doi.org/10.1787/9789264229358-en, 450.

${ }^{4}$ R. Cumbley and P. Church, "Is big data creepy?", Computer Law \& Security Review 29 (2013), 601-609.
} 
opportunities, thus becoming more competitive. The data generated every second can be structured data, those with pre-established strict standards, or unstructured data, ${ }^{5}$ such as emails, images, videos, audio, and documents. This data can increase the exposure of personal privacy, ${ }^{6}$ corporate information and secrets of States. ${ }^{7}$ As the executive office of the president of the United States stated, "used well, big data analysis can boost economic productivity, drive improved consumer and government services, thwart terrorists, and save lives". ${ }^{8}$

Since its beginning in 2001, ${ }^{9}$ Big Data has been identified as a 3 V's model, but especially from a legal perspective of analysis, Big Data adopted other three characteristics ${ }^{10}$ and can be better identified for its virtuosity as a 6 V's model.

The 6 V's model that describes Big Data is: (i) volume (great volume) generation and mass data capture; (ii) velocity (rapid generation, processing of data) the rapid data capture opportunity to maximise its usefulness; (iii) variety (various modalities, types of data) the various data formats, namely, structured, semi-structured and unstructured; (iv) value, which means to extract value from a huge volume of data through high-speed in the capture and analysis; (v) veracity, the reliability of the data obtained to ensure the truth in their analysis to obtain accurate information; and (vi) validation, the ability to assure that multiple data sources when grouped together make sense. ${ }^{11}$

\footnotetext{
${ }^{5}$ J. Fishleigh, A Non-Technical Journey into the World of Big Data: An Introduction (Cambridge: Legal Information Management, 2014), 150

${ }^{6}$ T. Craig and M. E. Ludloff, Privacy and Big Data (Sebastopol, CA: O’Reilly, 2011).

${ }^{7}$ H. Moon and H. S. Cho, "Big data and policy design for data sovereignty: A case study on copyright and CCL in South Korea”, Social Com, 2013, 1026-1029.

${ }^{8}$ The White House: Executive Office of the President, Big Data: Seizing Opportunities, Preserving Values, 2014, https://obamawhitehouse.archives.gov/sites/default/files/docs/big_data_privacy_ report_may_1_2014.pdf, 5 .

${ }^{9}$ M. Chen, S. Mao, Y. Zhang and V.C.M. Leung, Big Data: Related Technologies, Challenges and Future Prospects (London: Springer, 2014), 3-4.

${ }^{10}$ C. Agnellutti, Big Data: An Exploration of Opportunities, Values and Privacy Issues (New York: Nova Science Pub Inc., 2014).

${ }^{11}$ In 2017 Tom Shafer published in the Elder Research blog that the world now operates in an ever more sophisticated world of analytics, and to keep up with the times, he has presented an updated 2017 list: The 42 V's of Big Data and Data Science. The vast list, notwithstanding, seems an overstatement and consists in many V's that do not represent the V's for characterising the Big Data, especially from a legal perspective, such as: Version Control; Vet; Vexed; Vibrant; Viral; Vogue; Voodoo; Voyage; and Vulpine. Accessed November 21, 2018. https://www.elderresearch. com/company/blog/42-v-of-big-data.
} 
As explained by the OECD, ${ }^{12}$ the collaborative arrangements of firms combining their individual offerings to create coherent, customer-tailored solutions in Big Data as the data ecosystem is seen as "a combination of layers corresponding to key roles of actors, where the underlying layers provide goods and services to the upper layers". The global data ecosystem is growing fast due to the increasing number of players, many of them playing multiple roles in the Big Data market. According to a report by the International Data Corporation (IDC) and Open Evidence, ${ }^{13}$ the value of the data market in Europe, estimated in EUR 60 billion in 2016, will be of EUR 106 billion in 2020, impacting the entire continental economy, which will reach $4 \%$ of the GDP.

The importance of the competitive advantages of data linked with data collection and exploitation is a significant subject, where the role of information flowing through them and how it gets translated into decisions can be understood as the key difference between conventional markets and the data-rich ones. ${ }^{14}$

The network effects ${ }^{15}$ and the evolution of the digital economy with its dynamic competition is based on continuous cycles of innovation, development and ruptures, as well as market concentration, involving different players with dominant positions. This has led to a growing imbalance between large companies on the one hand, and small and medium-sized businesses and consumers on the other.

Personal data as an asset can be comprehended in two perspectives: from the consumer side and from the business side.

The refusal by a consumer to accept the terms and conditions that are imposed by a company for the access and use of a product, such as an app, may result in that consumer no longer relating to other people, which means that someone could be excluded from social networks or even kept apart from professional relations.

\footnotetext{
${ }^{12}$ OECD (2015), Data-Driven Innovation, 34.

13 "Big data: Interim report in the context of the joint inquiry on 'Big data' launched by the AGCOM deliberation No. 217/17 / CONS17". 2018. Accessed November 27. 2018. https:// www.agcom.it/documents/10179/10875949/Allegato+4-9-2018/f9befcb1-4706-4daa-ad38c0d767add5fd?version=1.0, III.

${ }^{14}$ V. Mayer-Schönberger and T. Ramge, Reinventing Capitalism in the Age of Big Data (New York: Basic Books, 2018), 7.

${ }^{15} \mathrm{~S}$. Vezzoso, "Internet competition and e-books: Challenging the competition policy acquis?", in G. Surblyté, Competition on the Internet. MPI Studies on Intellectual Property and Competition Law, vol. 23, Berlin: Springer, 2015, 33.
} 
The NY Times stated that in the age of internet capitalism people are in an inescapable thrall to one of the handful of American technology companies that now dominate much of the global economy, referred to by the newspaper as the Frightful Five: Amazon, Apple, Facebook, Microsoft and Alphabet, the holding company of Google. "Their growth has prompted calls for greater regulation and antitrust intervention". ${ }^{16}$

The business perspective empowered by mergers, acquisitions and market dominance, especially platforms, directly affects competition of smaller players, which can hardly compete with those players that act on different levels of the market and have Big Data in their benefit. ${ }^{17}$

Data is the commodity that spawns a lucrative, fast-growing industry, which prompts antitrust regulators to step in to restrain those who control its flow, as reported in The Economist. The giants that deal in data, the oil of the digital era, are Alphabet (Google), Amazon, Apple, Facebook and Microsoft, the world's five most valuable listed companies. "Their profits are surging: they collectively racked up over $\$ 25 \mathrm{bn}$ in net profit in the first quarter of 2017. Amazon captures half of all dollars spent online in America. Google and Facebook accounted for almost all the revenue growth in digital advertising in America last year". ${ }^{18}$

The circumstances in which a company - especially with existing market power - controls the collection of consumer data in a market where data is a considerable input into the products/services produced is undoubtedly the most worrying for end users and in some specific circumstances may warrant antitrust intervention. ${ }^{19}$ Nevertheless, as noticed by the European Data Protection Supervisor (EDPS), ${ }^{20}$ the truth is that "A full market analysis for any of the 'free' digital services has yet to be carried out".

This summarises why companies have decided to merge or why companies are acquired in the Digital Economy. These preliminary remarks

16 “Tech’s Frightful Five: They've Got Us”, The NY Times, May 10, 2017. Accessed May 30, 2017. https://www.nytimes.com/2017/05/10/technology/techs-frightful-five-theyve-got-us.html?_r=0.

${ }^{17} \mathrm{~V}$. Bagnoli, "Competition for the effectiveness of big data benefits", International Review of Intellectual Property and Competition Law 46, no. 6 (2015): 629-631.

18 "The world's most valuable resource is no longer oil, but data", The Economist, May 6, 2017. Accessed May 21, 2017. http://www.economist.com/news/leaders/21721656-data-economydemands-new-approach-antitrust-rules-worlds-most-valuable-resource.

${ }^{19} \mathrm{G}$. Pitruzzella, "Big data, competition and privacy: A look from the antitrust perspective". Concorrenza e Mercato, 23 (2016), special edition Big Data e Concorrenza, 15-27.

${ }^{20}$ EDPS, "Preliminary Opinion of the European Data Protection Supervisor Privacy and Competitiveness in the Age of Big Data: The Interplay between Data Protection, Competition Law and Consumer Protection in the Digital Economy", 2014, 26. 
will help comprehend some reasons that drove Case M. 7217 itself and the questions that have arisen since the EU decision on the Facebook/ WhatsApp acquisition.

\section{Case M.7217 - Facebook/WhatsApp acquisition}

On August 29 ${ }^{\text {th }}$ 2014, the European Commission (EC) received a notification of the proposed concentration by which Facebook, Inc. ("Facebook", USA) had acquired WhatsApp Inc. ("WhatsApp", USA) by way of a share purchase of US\$ 19 billion, which contributed to Facebook's strategy of focusing its business on mobile development. ${ }^{21}$

Facebook is a provider of websites and applications for mobile devices ("apps") offering social networking, consumer communications and photo/video sharing functions, and provides online advertising space. It offers the social networking platform called "Facebook", the consumer communications app "Facebook Messenger" and the photo and videosharing platform "Instagram". WhatsApp is a provider of consumer communications services via the mobile app called "WhatsApp", but does not sell advertising space.

The Commission's analysis focused on three sectors: (i) consumer communications services, (ii) social networking services, and (iii) online advertising services.

Consumer communications services are multimedia communications solutions that allow people to reach other contacts in real time. At the beginning those services were developed and offered as software applications for personal computers ("PCs"), but were progressively shifted away from PCs towards smart mobile devices, especially smartphones and tablets, becoming "consumer communications apps" that enable communication in various forms, such as voice and multimedia (text, photo or video)

\footnotetext{
${ }^{21}$ Pursuant to Council Regulation (EU) no. 139/2004 on the control of concentrations between undertakings (the EU Merger Regulation), in its Article 3.1 a concentration shall be deemed to arise where a change of control on a lasting basis results from: (a) the merger of two or more previously independent undertakings or parts of undertakings, or (b) the acquisition, by one or more persons already controlling at least one undertaking, or by one or more undertakings, whether by purchase of securities or assets, by contract or by any other means, of direct or indirect control of the whole or parts of one or more other undertakings. Following a referral pursuant to Article 4.5 with regard to a concentration as defined in Article 3 which does not have a Community dimension within the scope of Article 1 and which is capable of being reviewed under the national competition laws of at least three Member States, the persons or undertakings referred to in paragraph 2 may, before any notification to the competent authorities, inform the Commission by means of a reasoned submission that the concentration should be examined by the Commission.
} 
messaging, video chat, group chat, voice call, and sharing of location. Consumer communications services can be related to "free goods", since many of those apps are "zero cost" for consumers.

Social networking services are usually defined as services which allow users to connect, share, communicate and express themselves online or through a mobile app, usually provided without any monetary charges "free products", but normally monetised through advertising, charges for premium services and, it is important to highlight, through personal data.

Facebook's activities in online advertising services consist in the provision of services on Facebook's social networking platform but did not include any ads on Facebook Messenger app at the time of the EC's analysis on the Facebook/WhatsApp deal.

On October $3^{\text {rd }}, 2014$, the EC concluded that the deal would raise no competition concerns and authorised the proposed acquisition of WhatsApp by Facebook ruling that Facebook Messenger and WhatsApp were not close competitors and that consumers would continue to have a wide choice of alternative for consumer communications apps after the merger. The $\mathrm{EC}^{22}$ observed that consumer communications apps are characterised by network effects, the analysis of the proposed acquisition showed that Facebook and WhatsApp even as one entity would continue to face enough competition after the deal.

\section{Sizing up the EU decision on the Facebook/WhatsApp acquisition}

The European Commission (EC) decision on the Facebook/WhatsApp ${ }^{23-24}$ acquisition "decided not to oppose the Transaction and to declare it compatible with the internal market and with the EEA Agreement"25 focused on three sectors considered significant, defining the relevant market as: (i) consumer communications services; (ii) social networking; and (iii) online advertising services.

\footnotetext{
22 "Mergers: Commission approves acquisition of WhatsApp by Facebook", 2014, under "Press Release Database”, Press-release_IP-14-1088. Accessed June 01, 2018. http://europa.eu/rapid/ press-release_IP-14-1088_en.htm.

${ }^{23}$ Commission decision of 6 October 2014, pursuant to Article 6(1)(b) of Council Regulation No 139/2004, Case no. COMP/M.7217, Facebook/WhatsApp. http://ec.europa.eu/competition/mergers/cases/decisions/m7217_20141003_20310_3962132_EN.pdf.

${ }^{24}$ In the published version of the decision used for the analysis and development of the present article, some information has been omitted pursuant to Article 17(2) of Council Regulation (EC) No. 139/2004 concerning non-disclosure of business secrets and other confidential information.

${ }^{25}$ Case no. COMP/M.7217, Facebook/WhatsApp, paragraph 191.
} 
The EC focused its consumer communications services assessment on apps for smartphones and concluded that Facebook Messenger and WhatsApp are not close competitors since Facebook Messenger is a standalone app integrated with the Facebook social network and WhatsApp access is provided through phone numbers. Despite their popularity, both WhatsApp and Facebook Messenger already have large customer bases. The $\mathrm{EC}^{26}$ observed that a number of factors mitigate the network effects in this particular case: (i) the consumer communications apps market is fast growing and characterised by short innovation cycles in which market positions are often rearranged; (ii) launching a new app is reasonably simple and does not require significant time and investment; and (iii) customers can and do use multiple apps at the same time and can switch from one app to another without difficulty.

The EC concluded that the company's market boundaries of social networking services are continuously evolving, and Facebook and WhatsApp are, if anything, distant competitors in this area, and "whether or not WhatsApp is considered a social network, competition is unlikely to be negatively affected by the merger of such services". ${ }^{27}$

Finally, the ruling determined that even though WhatsApp is not active in the online advertising market, if Facebook were to introduce advertising on WhatsApp and/or start collecting WhatsApp user data, the merger would not raise competition concerns since: (i) a sufficient number of alternative providers to Facebook for the supply of targeted advertising would be still available; and (ii) Facebook does not have exclusive control over a large amount of internet user data that is valuable for advertising purposes.

It is worthwhile to highlight that the investigation conducted by the EC analysed potential data concentration issues only to the scope that they could weigh down competition in the online advertising market. Any privacy-related concerns from the increased concentration of data within the control of Facebook as a result of the deal with WhatsApp were not an issue for EU competition law.

\footnotetext{
${ }^{26}$ Press-release_IP-14-1088.

${ }^{27}$ Press-release_IP-14-1088.
} 


\subsection{Consumer communications services}

The EC determined market segmentation by functionality, by platform or by operating system. The most relevant for the evaluation of the deal Facebook/WhatsApp is segmentation based on platforms because WhatsApp is offered only for smartphones and there are no plans to expand its offering to other platforms. Therefore, as the EC noted, "the present case can be assessed on the basis of a relevant product market including only consumer communications apps for smartphones". ${ }^{28}$

The EC's analysis pointed out that different services such as text messaging, photo or video messaging or calls may take different approaches to facilitating consumer communications. This, however, does not put those services into different markets or market segments, and there was a range of competitors whose functionalities greatly overlapped with those offered by Facebook and WhatsApp.

The EC assessed the effects of the deal in the narrowest relevant product market for consumer communications services when they employed the market for consumer communications apps for smartphones. Consumer communications apps are mainly offered free of charge and not priced per messages. They considered that the combined position of Facebook and WhatsApp would be attenuated in a market including traditional electronic communications services such as voice calls, SMS, MMS, or e-mails.

It is necessary to highlight that no mention was made by the EC of big data and its impact on consumer communications apps for smartphones.

The geographic market definition for consumer communications apps also did not consider that certain consumer communications apps enjoy a greater reach than others in certain world regions. This is contrary to the analysis conducted by the EC which revealed that no major differences existed in the offering of consumer communications apps across the world. The consumer communications apps offered do not differ depending on the region or country concerned, either in terms of price, functionalities, platforms or operating system. "In this context, while there are indications that the geographic scope of the consumer communications apps market could be global, the Commission considers that the relevant geographic market for the assessment of the case is EEA-wide in line with a more conservative approach". ${ }^{29}$

\footnotetext{
${ }^{28}$ Case no. COMP/M.7217, Facebook/WhatsApp, paragraph 21.

${ }^{29}$ Case no. COMP/M.7217, Facebook/WhatsApp, paragraph 40.
} 
Once again it needs to be emphasised that no mention was made by the EC of big data and its concerns to consumer communications apps for smartphones. If there are substitutes among apps, one should evaluate the characteristics of a digital economy, such as the "network effects" and the transaction costs to replace an app even at "zero cost" for consumers. These may all characterise a barrier to entry and the existence of a dominant position.

The analysis of the EC on the competitive assessment of consumer communication services considered that Facebook and WhatsApp operate two consumer communications apps, Facebook Messenger and WhatsApp itself. These are in competition with several other players worldwide such as LINE, Viber, Threema, Telegram, Snapchat and WeChat. These players in turn compete with companies that provide smartphone hardware and operating systems as Apple with iMessage, BlackBerry with BBM, Samsung with ChatON, Google with Google Hangouts and the Android messaging platform, Microsoft with Skype.

The competitive interaction between consumer communications apps appears to be an attempt to offer the best communication experience and a cultivation of improvement seeking the largest user base that is a key innovation driver.

On the one hand, a consumer communications app is perceived as a trend amongst users and an important factor in attracting other users, which shapes the competitive environment. On the other hand, price is a factor that strongly contributes to the popularity of a consumer communications app given that users in general are very price-sensitive since they expect a free app.

At this point, one can perceive a strong correlation between "net effect" and "free products".

The EC ruled that high market shares were not necessarily indicative of market power. They determined no lasting damage to competition due to the recent and fast-growing sector, which is characterised by frequent market entry and short innovation cycles.

This contradicts the figures ${ }^{30}$ that show that the combined share of Facebook and WhatsApp in the EEA market for consumer communications apps on iOS and Android smartphones in the period between November 2013 and May 2014 was around [30-40]\% (WhatsApp: [20-30]\%;

\footnotetext{
${ }^{30}$ Case no. COMP/M.7217, Facebook/WhatsApp, paragraph 99.
} 
Facebook Messenger: [10-20]\%), followed by Android's messaging platform ([5-10]\%), Skype ([5-10]\%), Twitter ([5-10]\%), Google Hangouts ([5$10] \%)$, iMessage ([5-10]\%), Viber ([5-10]\%), Snapchat ([0-5]\%) and other market players with a share of $[0-5] \%$ or less.

The EC concluded that consumers' ability to switch providers implied no significant costs which could prevent consumers from changing among different consumer communications apps. However, switching providers may not be as easy in terms of convenience due to the need for users to reconstruct their network.

The consumer communications apps market has been characterised by disruptive innovation and there are no significant conventional barriers to entry for a new consumer communications app to be accessible for download.

Some information collected by the analysis developed by the EC indicated that barriers to entry would be represented by a lack of data portability and interoperability among consumer communications apps. However, the EC remarks that the deal would have an impact on the interoperability issues only if Facebook decided to merge the two platforms or allowed cross-platform communication.

Finally, the EC concluded that the Facebook/WhatsApp deal does not give rise to serious compatibility doubts in the EU internal market concerning the market for consumer communications apps.

\subsection{Social networking}

Facebook's social networking service consists of: (i) user profile (user online identity), information about jobs, schools and universities attended, relationship status, birthday, life events and likes and interests such as music and movies; (ii) newsfeed, which consists of regularly updated personalised stories such as posts, photos, friends information, pages and entities that the user is connected to; and (iii) timeline, which allows users to organise and display events and activities such as interests, photos, education, work history, relationship status, and contact information. WhatsApp is not active in social networking and is notably focused on facilitating fast and simple communications between and among users. Other entrepreneurs in social networking service are Google+, LinkedIn, MySpace, Pinterest and InterNations.

The differences in social networking services and consumer communications apps are becoming indistinct since each service adopts traditional 
functionalities of the other such as exchanging content of text messages, video, audio and photos. But the reasoning of the EC states that "on a general level, social networking services tend to offer a richer social experience as compared to consumer communications apps". ${ }^{31}$

Following this line of thought, the conclusion on product market definition adopted by the EC was that since the Facebook/WhatsApp deal would not give rise to serious doubts as to its compatibility with the internal market under any alternative market definition, a potential market can be left open.

The geographic market definition the EC adopted was a more conservative approach to consider the EEA-wide market for social networking services, even with indications that it could be global.

The competitive assessment analysis by the EC observed that Facebook operates - at the time of the analysis - the world's largest social network, which connects over 1.3 billion users worldwide and from 200 to 300 million in the EEA.

If consumer communications apps such as WhatsApp are included in the market for social networking services, the number of alternative service providers is high. Notwithstanding, the EC concluded that these providers are not close competitors in the potential market for social networking services due to the significant differences between the functionalities and the focus of Facebook and WhatsApp.

It is important to highlight that the EC considered that the integration of WhatsApp could strengthen Facebook's position in the potential market for social networking services. However, as evidenced during the analysis nothing supported a future integration and, in any event, an integration of WhatsApp with Facebook would be mitigated by the fact that many WhatsApp's active users are already users of Facebook eliminating any potential net gain in terms of new members.

In sum, the EC considered that the deal Facebook/WhatsApp "would not give rise to serious doubts as to its compatibility with the internal market as regards the potential market for the provision of social networking services". ${ }^{32}$

\footnotetext{
${ }^{31}$ Case no. COMP/M.7217, Facebook/WhatsApp, paragraph 54.

${ }^{32}$ Case no. COMP/M.7217, Facebook/WhatsApp, paragraph 163.
} 


\subsection{Online advertising services}

Facebook collects and analyses data on the users of its social networking platform to provide advertisements on behalf of advertisers. Each user is targeted, but the data is neither sold nor does Facebook provide data analytics services to advertisers or other third parties as a separate product from the advertising space itself.

During the time of the investigation WhatsApp did not sell any form of advertising or store or collect data on its users that would be valuable for advertising purposes, besides messages that are not stored in WhatsApp's servers, but only on the users' mobile devices or chosen cloud.

The reasoning of the EC on the provision of data or data analytics services was not to investigate any possible market definition since neither Facebook nor WhatsApp were active in such both potential markets.

The conclusion on product market definition adopted by the EC was that online advertising constitutes a relevant market separate from offline advertising and "whether segments of that market constitute relevant markets in their own right can be left open for the purposes of this decision, because the Transaction would not give rise to serious doubts as to its compatibility with the internal market under any such narrower product market definition". ${ }^{33}$

The reasoning of the EC in geographic market definition was to define the online advertising market and its possible sub-segments as national in scope or alongside linguistic borders within the EEA. They considered that some factors such as customers' - purchasing preferences, customers' languages and the presence of support and sales networks were located at the national level.

The competitive assessment analysis developed by the EC considered the potential data concentration to reinforce Facebook's position in the online advertising market or in any sub-segments thereof.

It is important to observe that the EC considered that any privacy-related concerns from the increased concentration of data within the control of Facebook because of the deal with WhatsApp would be the scope of the $\mathrm{EU}$ data protection rules and not a matter of EU competition law rules.

Since WhatsApp was not a player in the provision of online advertising services, no horizontal overlap was verified. Furthermore, considering that WhatsApp neither collects data on its users nor stores the content of

${ }^{33}$ Case no. COMP/M.7217, Facebook/WhatsApp, paragraph 79. 
messages, non-valuable data for advertising purposes is generated, meaning that the deal does not increase the amount of data potentially available to Facebook for advertising purposes. Nevertheless, to verify if the deal with WhatsApp could increase Facebook's position in the online advertising market the EC analysed two main possible theories of harm: (i) introducing advertising on WhatsApp, and/or (ii) using WhatsApp as a potential source of user data for improving the targeting of Facebook's advertising activities outside WhatsApp.

The possible theory of harm of introducing advertising on WhatsApp could be possible by the analysis of the collected data from WhatsApp's users and the result would strengthen Facebook's position in the online advertising market or sub-segments thereof. Notwithstanding, despite introducing advertising on WhatsApp the EC concluded that "there will continue to be a sufficient number of other actual and potential competitors who are equally well placed as Facebook to offer targeted advertising" ${ }^{34}$

Finally, the second theory of harm of using WhatsApp as a potential source of user data for improving the targeting of Facebook's advertising activities outside WhatsApp. Even though the only data WhatsApp has on its users is their names and the mobile phone numbers associated with the accounts, several respondents, as informed by the EC, expect that the increased amount of data which will come under Facebook's control resulting from the deal with WhatsApp will materially reinforce Facebook's position in the provision of online advertising services.

The EC reasoning was that even if Facebook started to utilise WhatsApp user data to improve targeted advertising on Facebook's social network, there will continue to be a significant number of market participants that collect user data and that are not within Facebook's exclusive control as Google, Apple, Amazon, eBay, Microsoft, AOL, Yahoo!, Twitter, IAC, LinkedIn, Adobe and Yelp. In conclusion, the EC considered that the Facebook/WhatsApp deal "does not give rise to serious doubts as to its compatibility with the internal market as regards the market for the provision of online advertising services, including its potential sub-segments". ${ }^{35}$

\footnotetext{
${ }^{34}$ Case no. COMP/M.7217, Facebook/WhatsApp, paragraph 179.

${ }^{35}$ Case no. COMP/M.7217, Facebook/WhatsApp, paragraph 190.
} 


\section{Questions that have arisen since the EU decision on the WhatsApp acquisition by Facebook}

Despite the fact that competition authorities started to analyse on a case by case basis the possible competition issues that may arise from possession and use of data, as concluded by the Autorité de la Concurrence and the Bundeskartellamt, ${ }^{36}$ in the end none were determined in the specific cases. Nevertheless, while many internet services are provided for "free" for consumers, in practice they involve the collection of personal data. ${ }^{37}$ "This has spurred new discussions about the role of data in economic relationships as well as in the application of competition law to such relationships, in particular as regards the assessment of data as a factor of market power". ${ }^{38}$

Since the decision of the European Commission (EC) of not opposing to the Facebook/WhatsApp deal and declaring it compatible with the internal market and with the EEA Agreement, some investigations were opened by national competition authorities and one investigation by the EC.

In December 2016, the EC addressed a Statement of Objections to Facebook since it found that, contrary to Facebook's statements in the 2014 merger review process, the technical possibility of automatically matching Facebook and WhatsApp users' identities already existed in 2014, and that Facebook's staff had been aware of such a possibility. In August 2016, WhatsApp publicised updates to its terms of service and privacy policy, including the possibility of linking WhatsApp users' phone numbers with Facebook users' identities.

The EU Merger Regulation ${ }^{39}$ obliges companies in a merger investigation to deliver correct information that is not confusing or false as this is essential for the EC to review mergers and takeovers in a timely and effective manner. This duty applies regardless of whether the information has an impact on the ultimate outcome of the merger assessment.

\footnotetext{
${ }^{36}$ Autorité de la Concurrence and Bundeskartellamt, Competition Law and Data. 10th May, 2016, 3. http://www.bundeskartellamt.de/SharedDocs/Publikation/DE/Berichte/Big\%20Data\%20 Papier.pdf?__blob=publicationFile\&v=2.

37 "If a market for personal data could be defined in the abstract, the next decisive step would be the delineation of the exact boundaries of this market and by that the identification of the relevant players in terms of significant competitive interactions". S. Vezzoso, "Pro-competitive regulation of personal data protection in the EU", in J. Drexl and V. Bagnoli, State-Initiated Restraints of Competition (Cheltenham: Edward Elgard, 2015), 2014.

${ }^{38}$ Autorité de la Concurrence and Bundeskartellamt, Competition Law and Data, 10th May, 2016, 3 .

${ }^{39}$ The EC Merger Regulation. Accessed November 11, 2018. https://eur-lex.europa.eu/legal-content/EN/TXT/PDF/?uri=CELEX:32004R0139\&from=EN.
} 
In May 2017 the EC fined Facebook in EUR 110 million for providing incorrect or misleading information during the EC's 2014 investigation under the EU Merger Regulation of Facebook's acquisition of WhatsApp. ${ }^{40}$ With respect to all three services the EC carried out its competitive assessment - (i) consumer communications services; (ii) social networking services; and (iii) online advertising - also assuming a scenario where automated user matching would be possible.

The EC stated that, even in this scenario of matching, its conclusions as to the absence of anti-competitive effects of the proposed deal would stand.

In Germany the Bundeskartellamt initiated in March 2016 a proceeding against Facebook - Facebook Inc., USA, the Irish subsidiary of the company, and Facebook Germany GmbH, Hamburg - on suspicion of abuse of market power by infringing data protection rules with its specific terms of service on the use of user data.

The initial suspicion was that Facebook had abused its possibly dominant position in the market for social networks by violating data protection provisions in the use of unlawful terms and conditions that could represent an abusive imposition of unfair conditions on users.

According to the Bundeskartellamt, some indications of market analysis show that Facebook has a dominant market position in the separate market for social networks. Through the collection of a large amount of personal user data from various sources and the creation of user profiles Facebook facilitates its advertising customers on targeting their businesses sharply.

To have access to Facebook social network, users must agree to Facebook's collection and use of their data by accepting the terms of service. Even if it can be considered a matter of data protection law, as observed by the Bundeskartellamt, "if there is a connection between such an infringement and market dominance, this could also constitute an abusive practice under competition law". ${ }^{41}$

\footnotetext{
40 "Mergers: Commission fines Facebook $€ 110$ million for providing misleading information about WhatApp takeover", 2017, under "Press Release Database”, Press-release_IP-17-1369. Accessed November 11, 2018. http://europa.eu/rapid/press-release_IP-17-1369_en.htm.

41 "Bundeskartellamt initiates proceeding against Facebook on suspicion of having abused its market power by infringing data protection rules”, 2016, Pressemitteilungen/2016/02_03_2016. Accessed December 26, 2018. http://www.bundeskartellamt.de/SharedDocs/Meldung/EN/ Pressemitteilungen/2016/02_03_2016_Facebook.html?nn=3599398.
} 
As stated by Mundt: "Dominant companies are subject to special obligations. These include the use of adequate terms of service as long as these are relevant to the market. User data is hugely important for advertising financed internet services such as Facebook. For this reason, it is essential to also examine under the aspect of abuse of market power whether the consumers are sufficiently informed about the type and extent of data collected". 42

In December 2017, the Bundeskartellam ${ }^{43}$ informed Facebook of its preliminary legal assessment in the abuse of dominance proceeding. Based on the current stage of the proceedings the Bundeskartellamt assumes that Facebook is dominant in the German market for social networks. In the view of the competition authority, Facebook is abusing this dominant position by making the use of its social network conditional on it being allowed to limitlessly amass all kinds of data generated by using thirdparty websites ${ }^{44}$ and merging it with the user's Facebook account.

Finally, in February 2019, the Bundeskartellamt imposed on Facebook far-reaching restrictions in the processing of user data. ${ }^{45}$

The decision in Germany covers different data sources: (i) Despite Facebook-owned services like WhatsApp and Instagram can continue to collect data, the assigning data to Facebook user accounts is subjected to the users' voluntary consent. The non-consent implies the data remain with the respective service and cannot be processed in combination with Facebook data. (ii) Users must give a voluntary consent to the collecting data from third party websites and assigning them to a Facebook user account.

Facebook will have to substantially restrict its collection and combining of data when a consent is not given for data from Facebook-owned services and third party websites.

\footnotetext{
${ }^{42} \mathrm{Ibid}$.

43 "Preliminary assessment in Facebook proceeding: Facebook's collection and use of data from thirdpraty sources is abusive”, 2017, Pressemitteilungen/2017/19_12_2017. Accessed July 14, 2018. https:// www.bundeskartellamt.de/SharedDocs/Meldung/EN/Pressemitteilungen/2017/19_12_2017_ Facebook.html?nn=3591568.

${ }^{44}$ According to the Bundeskartellamt the third-party sites include firstly services owned by Facebook such as WhatsApp or Instagram, and secondly websites and apps of other operators with embedded Facebook APIs.

45 "Bundeskartellamt prohibits Facebook from combining user data from different sources", 2019. https://www.bundeskartellamt.de/SharedDocs/Publikation/EN/Pressemitteilungen/2019/07_02_ 2019_Facebook.pdf?__blob=publicationFile\&v=2.
} 
According to the Bundeskartellamt, "the extent to which Facebook collects, merges and uses data in user accounts constitutes an abuse of a dominant position". ${ }^{46}$

In Italy, in May 2017, the Autorità Garante della Concorrenza e del Mercato (AGCM) fined WhatsApp EUR 3 million for having forced its users to share their personal data with Facebook, closing 2 investigations opened in October 2016 concerning infringements of the Consumer Code. $^{47}$

One investigation alleged that WhatsApp forced its users to accept in full the new Terms of Use, specifically the condition to share their personal data with Facebook. According to the AGCM, WhatsApp induced its users to believe that without conceding such approval the service would be blocked. The other investigation consisted of an alleged unfair nature of some contractual clauses included in WhatsApp's "Terms of Use" and therefore considered the contract terms illicit.

Pitruzzella observed that "larger companies have access to larger datasets and therefore can offer more successful services to consumers, which in turn allow them to collect even more information and data. This selfreinforcing mechanism may be similar to a network effect driving market concentration". ${ }^{48}$

Despite the legal basis of the decisions of AGCM being consumer law, the analysis took in account the competition rulings of the EC on Case M.7217 - Facebook/WhatsApp. It is important to consider that AGCM plays a role of competition and consumer authority. The Bundeskartellamt mentioned in its press release that it had opened the Facebook preceding as an infringement of data protection law related with market dominance which could represent an abusive conduct under competition law.

As can be observed, the investigations in Germany and in Italy bring some challenges for competition authorities which somehow had already been mentioned at the Facebook/WhatsApp acquisition. This raises a suspicion as to whether the analysis covered all the complexities related to

\footnotetext{
${ }_{46}$ "Bundeskartellamt prohibits Facebook from combining user data from different sources", 2019. https://www.bundeskartellamt.de/SharedDocs/Publikation/EN/Pressemitteilungen/2019/07_02_ 2019_Facebook.pdf?__blob=publicationFile\&v=2, 2.

47 "WhatsApp fined for 3 million euro for having forced its users to share their personal data with Facebook", 2017, Press-releases/2380. Accessed June 06, 2017. http://www.agcm.it/en/ newsroom/press-releases/2380-WhatsApp-fined-for-3-million-euro-for-having-forced-its-usersto-share-their-personal-data-with-facebook.html.

${ }^{48}$ G. Pitruzzella, Big Data, Competition and Privacy, 19.
} 
data in the digital economy. In other words, three main questions have arisen since the EC decision on Facebook/WhatsApp acquisition: (i) Did the EC apply the best tools to analyse the case?; (ii) Could the EC have addressed a decision that would somehow interfere in the privacy field?; and (iii) Could the procedures in Germany and Italy had been avoided?

\subsection{Did the EC apply the best tools to analyse the case?}

The access to a large volume and variety of data is a competitive advantage in the market. Therefore, the collection of data may indicate barriers of entrance to new entrepreneurs that are unable to have access to the same kind of data as already established companies have, either collecting or paying for data. ${ }^{49}$

The definition of an additional input market for data is helpful to assess the competitive circumstances further than the relevant markets for the existing services offered to users and advertisers. This is notable when assessing proposed acquisitions and conduct of providers of online platforms under merger and abuse of dominance standards. In this regard, while commenting on the acquisition of Nest by Google, approved by the US Federal Trade Commission in 2014, Graef concludes that the US FTC "would have been able to assess such concerns by defining a relevant market for data". 50

As stated by the EDPS, "the definition of the relevant market is the first stage in the legal analysis of cases of anti-competitive agreements, mergers and abuse of dominant market position. This allows competition regulators to identify the market operators, that is, suppliers, customers and consumers, and to calculate the total market size and the market share of each supplier with reference to the relevant product or service in the relevant area". ${ }^{51}$

Taking into account that big data is not an undistinguished pool of data since there might be a diverse type of information that satisfies different needs of a variety of companies, Pitruzzella states that "the definition of

\footnotetext{
${ }^{49}$ Autorité de la Concurrence and Bundeskartellamt, Competition Law and Data, 10th May, 2016, 11 .

${ }^{50}$ I. Graef, "Market definition and market power in data: The case of online platforms", World Competition 38, no. 4 (2015): 494.

${ }^{51}$ EDPS, "Preliminary Opinion of the European Data Protection Supervisor. Privacy and Competitiveness in the Age of Big Data. The interplay between data protection, competition law and consumer protection in the Digital Economy", 2014. Accessed December 26, 2018. https:// edps.europa.eu/sites/edp/files/publication/14-03-26_competitition_law_big_data_en.pdf.
} 
relevant markets for data prompts the need to undertake a substitutability analysis in order to identify a relevant market for data (services) and assess the competitive constraint between the parties". ${ }^{2}$

The complexity underlying the value chain determines a very varied and articulated market scenario for big data where it is not always easy to identify the actors participating in the market. "However, the ecosystem of big data presents a degree of interconnection between the various parties involved making it difficult to identify individual well-defined markets; consequently, the resulting complexity determines a scenario in which the various segments of the system offer a possible representation, are often closely interrelated. This determines a market structure in which (few) large multinational companies, characterised by a high degree of vertical, diagonal and horizontal integration in all (or almost all) phases of the ecosystem, operate alongside a myriad of small specialized businesses that often, after the period of start-up, are acquired by the larger ones" ${ }^{53}$

Understanding the whole structure of the relevant market of Big Data facilitates comprehending how in fact it works. It determines the players acting on each level or stage of the market, if the available data confer a significant competitive advantage or even market power for the owner of it and if that data is an essential facility to new entrants or for competitors that remain in the market. ${ }^{54}$

The Big Data cycle begins with the generation of data, whether structured data, such as scientific research, or unstructured data, such as emails sent and received. Its goal is the use or consumption of such data, once processed into valuable information for companies, retail chains and governments, for instance. They use them in many ways, from the development of public policies to a competitive advantage to win customers and expand market share. Both the beginning and the end of Big Data by analogy would be the beginning of an economic activity in nature itself, in this case data, and it ends with the final consumer, which means the use or consumption of the information generated by the Big Data.

\footnotetext{
${ }^{52}$ G. Pitruzzella, Big Data, Competition and Privacy, 20.

53 "Big data: Interim report in the context of the joint inquiry on 'Big data' launched by the AGCOM deliberation No. 217/17 / CONS17”. Accessed November 27, 2018. https://www.agcom.it/documents/10179/10875949/Allegato+4-9-2018/f9befcb1-4706-4daa-ad38-c0d767add5fd?version=1.0. ${ }^{54}$ Autorité de la Concurrence and Bundeskartellamt, Competition Law and Data, 10th May, 2016, $15-16$.
} 
The structure of the Big Data market, therefore, can be segmented into three parts where in fact the process of Big Data occurs, namely: (i) Big Data capture; (ii) Big Data storage; and (iii) Big Data analytics. In each of these phases (or stages or levels) the productive chain or economic activity that is the Big Data market includes consumers, entrepreneurs, public institutions, non-profit organizations, and governments, among others. While some of these players are involved in only one or some sectors of this market, other competitors are engaged in the whole chain, acting in the different stages of the so-called Big Data Relevant Market.

The Big Data Capture is the first level or stage of the Big Data Relevant Market, where data is captured, both personal and public data, from the use of mechanisms developed for this purpose. This process, sometimes called collection, access or acquisition of data is the recording of data that goes into a computer system.

This process of capturing data occurs in all sectors of the economy and the data is gathered from a multitude of sources. Some examples of data capture are: (i) cell phones companies, which have detailed data about customers, including their location and call log; (ii) internet service companies that may have access to detailed information of internet usage by its customers; (iii) store chains, airlines, and gas stations, which, for example, hold their detailed consumer information, such as purchase profiles, from cards and loyalty programmes.

The Big Data Storage is the second level or stage of the Big Data Relevant Market, where the data captured is stored, and which will be accumulated, aggregated into large quantities, organised and stored in datasets for later use.

A data storage service with enough space (or capacity or volume) needs to provide an effective access interface to analyse a large amount of data, such as transactions by credit or debit card, accounts, logins, authentic details, personal contacts, comments on social networks, posted photos and videos, stored for a wide range of providers' services, such as financial institutions and telephone companies, transportation companies, hospitals or medical clinics and government agencies.

The Big Data Analytics is the third level or stage of the Big Data Relevant Market, where the analysis of captured data that has been stored in datasets and combined with other information takes place to show trends for the analysis and development of profiles, records, macro trends, and which is applied for a variety of purposes. In this market, data merges from 
different public and private sources, such as consumers, companies, institutions, government agencies, and analytically infer valuable information.

The potential generated with the aggregation and analysis of data and the information obtained may be translated into new opportunities, new ideas and new solutions and become a competitive advantage for companies, leading to market power. Among the traditional players there are retailers, providers of management services to clients, software, business intelligence systems and loyalty programmes. New players which start to operate in the market are companies involved in online advertising, market research companies, and experts in data analysis, suppliers and data brokers.

The definition of the Big Data Relevant Market ${ }^{55}$ (or simply BDRM) can explain the whole picture of this market in its different stages. In addition, "the use of big data is becoming a key way for leading companies to outperform their peers" ${ }^{56}$ It brings together some awareness regarding market power and abuse of dominance as exclusionary practice since the issue is competition and goes beyond innovation and welfare.

Although the definition of Big Data Relevant Market has not been yet tested in any case analysed by a competition authority, the accurate analysis of the BDRM in three sub-markets or stages can help evaluate the whole market structure more precisely and estimate the undertakings' market power.

That is even more significant if considered that the information and knowledge originated from Big Data is not available to everyone in the same amount and quality. The accessibility to these technologies may give a competitive surplus to those who hold them. The precise identification of the players and their respective shares in the capture, in the storage and in the analysis of Big Data can better explain how the BDRM works and how concentrated it is. It is important to consider that one player can perform its business in only one, in several, or even in the three stages of the BDRM.

\footnotetext{
${ }^{55}$ V. Bagnoli, “The big data relevant market”, Concorrenza e Mercato 23 (2016), special number Big Data e Concorrenza, 73-94.

${ }^{56}$ McKinsey Global Institute, "Big Data: The Next Frontier for Innovation, Competition, and Productivity, May 2011, Report”, 2011, https://www.mckinsey.com/business-functions/digitalmckinsey/our-insights/big-data-the-next-frontier-for-innovation, 6.
} 
The BDRM signalises that the Big Data cycle not only deals with overlaps on horizontal bases, but also on vertical bases, revealing existing or potential enhancements of market power and dominance.

Identifying and understanding the Big Data Relevant Market structure (Big Data capture, Big Data storage and Big Data analytics) from the Competition Law perspective may also lead to better comprehend the performance of companies in the Big Data market and verify precise competition issues such as market power, barriers to entrance and abuses of dominance.

The definition of the relevant market is the beginning of any competitive analysis. This identifies what product or service people are dealing with, which players are in this market, such as producers, distributors and even consumers, their interests, the total market size, the existence of barriers to entry and the possibility of market power and dominant position. But did the EC consider the big data relevant market as a tool for the analysis of the Facebook/WhatsApp case?

The EU decision (COMP/M.7217) in the Facebook/WhatsApp deal focused on three sectors considered significant, defining the relevant market as: (i) consumer communications services; (ii) social networking; and (iii) online advertising services; but at the same time showed that an accurate analysis of Big Data was not held since it did not specify what the relevant market of Big Data could be.

The EC considered that the merger did not provoke any horizontal overlaps and analysed the potential data concentration only to the extent of a possible strengthening of market position in the online advertising market or in any sub-segments thereof, since only Facebook was an active provider of online advertising services.

Another two possible theories of harm were raised to verify if Facebook could strengthen its position in online advertising by: (i) introducing advertising on WhatsApp; and (ii) using WhatsApp as a potential supply of user data for the reason of improving Facebook's advertising activities.

Regarding the first possible theory of harm the EC concluded that: "regardless of whether the merged entity will introduce advertising on WhatsApp, there will continue to be a sufficient number of other actual and potential competitors who are equally well placed as Facebook to offer targeted advertising" ${ }^{57}$ Concerning the second possible theory of harm the

${ }^{57}$ Case no. COMP/M.7217, Facebook/Whatsapp, paragraph 179. 
reasoning of the EC was that: "regardless of whether the merged entity will start using WhatsApp user data to improve targeted advertising on Facebook's social network, there will continue to be a large amount of Internet user data that are valuable for advertising purposes and that are not within Facebook's exclusive control". ${ }^{58}$

The relevance of Big Data in merger investigations, as Pitruzzella states, is not restricted to how data is negotiated in a market, but includes how companies collect and analyse a vast amount of data and use it as an input to provide goods/services to end users and companies. "The fact that no market for data exists, does not imply that data is an irrelevant factor in assessing the effects of a merger. The claim that big data only rarely has anything to do with market definition or competitive effects because it usually is not traded in market is thus unfounded". ${ }^{59}$

The Big Data Relevant Market structure, segmented in Big Data capture, Big Data storage and Big Data analytics from the Competition Law perspective may also lead to better comprehend the performance of companies in the Big Data market and verify competition issues in the deal Facebook/WhatsApp more precisely, such as market power, barriers to entrance and abuses of dominance.

The EC focused its assessment of consumer communications services on apps for smartphones and concluded that Facebook Messenger and WhatsApp are not close competitors since Facebook Messenger is a standalone app integrated with the Facebook social network and WhatsApp access is provided through phone numbers. The EC concluded in social networking services that the market boundaries are continuously evolving, and Facebook and WhatsApp are, if anything, distant competitors in this area and competition is unlikely to be negatively affected by the merger. Even though WhatsApp is not active in online advertising, the EC reasoning was that if Facebook were to introduce advertising on WhatsApp and/ or start collecting WhatsApp user data, the merger would not raise competition concerns.

Nevertheless, considering that Facebook and WhatsApp were somehow competitors at the Big Data Capture stage, since Facebook also performs at the segments of Big Data Storage and Big Data Analytics, and pondering any strengthens of dominance in online advertising market resulting from

\footnotetext{
${ }^{58}$ Case no. COMP/M.7217, Facebook/Whatsapp, paragraph 189.

${ }^{59}$ G. Pitruzzella, Big Data, Competition and Privacy, 20.
} 
the acquisition of WhatsApp by Facebook, it can be considered a vertical concentration on the present relevant market of big data. Furthermore, if WhatsApp could represent - even if as a potential player - a company to capture personal data, it could reinforce Facebook's performance in online advertisement, or the merger itself could simply represent an exclusion of a potential competitor of the market.

The EU decision on the Facebook/WhatsApp acquisition could have been different if it considered the cycles of the BDRM - capture, storage and analysis.

\subsection{Could the EC have addressed a decision that somehow would interfere in the privacy field?}

In its decision, the EC stated that the deal would raise no competition concerns and authorised the proposed acquisition of WhatsApp by Facebook ruling that Facebook Messenger and WhatsApp are not close competitors and that consumers would continue to have a wide choice of alternatives for consumer communications apps after the acquisition. The EC analysed potential data concentration issues only to the scope that it could weigh down competition in the online advertising market. Any privacy-related concerns from the increased concentration of data within the control of Facebook because of the deal with WhatsApp is not a matter of the EU Competition Law.

Despite its reasoning, or absence of it, of dealing with privacy and consumers matters, should the EC have verified any privacy-related concerns from the increased concentration of data, it should have addressed the issue.

Mergers and acquisitions are ex-ante investigations which count on forecasts of the effect of the concentrated entity on the market. Join in competition on privacy into enforcement procedures are key answers for the competitive analysis of a case. Then, assessing to what extent a concentration of two companies competing for the same data would foreclose competition or affect the transparency of privacy policies and the motivation to invest in privacy enhancing technologies could better addressthe understanding of such case.

Whereas in Case C-32/11, Allianz Hungaria, the CJEU recognised that an infringement of one area of law could possibly be a factor in deciding that there had been a violation of competition law as well and that it was possible that a breach of data protection law could constitute an infringement of competition law, in Case C-238/05, Asnef-Equifax, the 
CJEU decided that, concerning the exchange of personal information on solvency and credit worthiness, any possible matters relating to the sensitivity of personal data are not an issue for competition law, as they may be resolved based on the relevant provisions leading data protection.

As observed in 2014 by the EDPS, "the Lisbon Treaty has created a positive obligation on the competition authorities including the Commission to uphold fundamental rights, and that privacy protection merited similar attention as the preservation of media plurality". ${ }^{60}$

In December 2018, the AGCM announced the decision of an investigation that had opened in April 2018 for alleged violations of Consumer Law by Facebook Ireland Ltd. and its parent company Facebook Inc. ${ }^{61}$ Facebook was considered to be violating Italian Consumer Law for misleading consumers into registering on the Facebook platform while not adequately and immediately informing them during the creation of the account that the data provided would be used for commercial purposes.

Facebook emphasised the free nature of the service; however, it was not clear about the commercial objectives underlying the provision of the social network service for using data to personalise the service and using data to carry out advertising campaigns. This induced users into making a transactional decision that they probably would not have taken.

AGCM also considered that Facebook had violated Consumer Law for carrying out an aggressive practice, namely the exertion of excessive influence on registering consumers without express and prior consent and the unconscious and automatic transmission of their data to third-parties (websites and apps) for commercial purposes. The total fine amount applied to Facebook for those violations was EUR 10 million.

The Data and Consumer Protection interface was observed by AGCM in its decision. ${ }^{62}$ Even if a company is in compliance with the privacy

\footnotetext{
${ }^{60}$ EDPS, "Report of EDPS workshop on privacy, consumers, competition and big data", 2014. Accessed December 26, 2018. https://edps.europa.eu/data-protection/our-work/publications/ reports/report-edps-workshop-privacy-consumers-competition-and_en, 6.

${ }_{61}$ "Facebook fined 10 million Euros by the ICA for unfair commercial practices for using its subscribers' data for commercial purposes", 2018, Press-releases/2018/12. Accessed December 17, 2018. http://en.agcm.it/en/media/press-releases/2018/12/Facebook-fined-10-million-Eurosby-the-ICA-for-unfair-commercial-practices-for-using-its-subscribers\%E $\% 80 \% 99$-data-forcommercial-purposes.

${ }^{62}$ AGCM, "PS11112 - Uso dei dati degli utenti a fini commerciali: sanzioni per 10 milioni di euro a Facebook”, 2018, datAllegati-news/PS11112. Accessed December 17, 2018. http://www.agcm.it/ dotcmsdoc/allegati-news/PS11112_scorr_sanz.pdf, items 45 and 46.
} 
legislation, it shall also comply with the rules on unfair commercial practices. The privacy policy guarantees the protection of personal data, which is defined as information related to a (physical or legal) person and qualified as fundamental rights. It is for the Personal Data Protection Authority to apply penalties for data violation. In the field of unfair commercial practices, Consumer Law aims to protect the consumer from economic choices induced by deceptive and aggressive practices that are not regulated in specific disciplines. Data and Consumer Protection have a different scope and pursue distinct interests. Consequently, there is no conflict between the two disciplines, rather integrating the same in a complementary manner.

The Bundeskartellamt in its decision from February 2019 also highlighted data protection provisions as a standard for examining exploitative abuse. In this sense, according to the German Competition Authority, Facebook's terms of service and the manner and extent to which it collects and uses data are in violation of the European data protection rules to the detriment of users. Observing the data protection issues involved, the Bundeskartellamt concluded, that Facebook's conduct represents an exploitative abuse. "Dominant companies may not use exploitative practices to the detriment of the opposite side of the market, i.e. in this case the consumers who use Facebook. This applies above all if the exploitative practice also impedes competitors that are not able to amass such a treasure trove of data. This approach based on competition law is not a new one, but corresponds to the case-law of the Federal Court of Justice under which not only excessive prices, but also inappropriate contractual terms and conditions constitute exploitative abuse (so-called exploitative business terms)" ${ }^{\prime 3}$.

EU approaches to data protection, competition and consumer protection share common goals, including the promotion of growth, innovation and the welfare of individual consumers. This has been stated by the EDPS. A closer dialogue between regulators and experts about policy boundaries can not only aid enforcement of rules on competition and consumer protection, but also stimulate the market for privacy-enhancing services. ${ }^{64}$

63 "Bundeskartellamt prohibits Facebook from combining user data from different sources", 2019. https://www.bundeskartellamt.de/SharedDocs/Publikation/EN/Pressemitteilungen/2019/07_02_ 2019_Facebook.pdf?__blob=publicationFile\&v=2, p. 3

64 "Report of EDPS workshop on privacy, consumers, competition and big data", 3. 
Competition law has long been of central importance to the EU. It has evolved by preventing public obstacles to interstate trade to ensure control of corporate mergers and liberalisation of sectors of the public economy. Its main aims are to enhance the efficiency of the internal market and the welfare of and choice available to consumers. However, the EDPS states that the "ultimate purpose of competition law is to ensure that the internal market will satisfy all reasonable wishes of consumers for competition, including not only the wish for competitive prices but also the wish for variety, innovation, quality and other non-price benefits, including privacy protection".

Even if the European Court of Justice has rarely referred to consumer welfare in its judgments on competition cases, the interface of Data, Consumer and Competition is certainly allowing the EC to address a decision that can somehow interfere in the privacy field. The "Commission [itself] recognizes in its guidelines on enforcement of rules on abuse of dominance, welfare is determined not only by price, but also by other factors, such as quality and consumer choice, which is also a relevant concern for data protection". ${ }^{65}$

As stressed by the EDPS, regarding the interfaces between competition law, consumer protection and data protection, it is possible to conclude that:

". The market for free services in an increasing number of sectors of the digital economy has yet to be analysed but clearly power is achieved through control over massive volumes of data on service users.

- The scope for abuse of market dominance and harm to the consumer through refusal of access to personal information and opaque or misleading privacy policies may justify a new concept of consumer harm for competition enforcement in digital economy.

- Application of competition rules to digital markets has the potential to promote privacy-enhancing services and greater consumer control over their own data". ${ }^{66}$

For this reason, in cases related to mergers such as Facebook/WhatsApp analysed by the EC, and if some competition infringement or restriction

\footnotetext{
65 "Report of EDPS workshop on privacy, consumers, competition and big data", 19 (brackets not in the original).

66 "Report of EDPS workshop on privacy, consumers, competition and big data", 26.
} 
is detected, the Competition Authority shall apply all the remedies considered possible to address issues related to consumer and data privacy. As highlighted by the EDPS, "in competition cases involving firms in the digital economy other remedial options could also be considered which address the harm to individuals' privacy".

The European Data Protection Board (EDPB), in its statement on the data protection impacts of economic concentration, observes that the increased market concentration in digital markets has the potential to threaten the level of data protection and freedom enjoyed by consumers of digital services. Considering that independent data protection authorities can help with the assessment of potential abuse of dominance as well as with company mergers, which may accumulate significant informational power, "the identification of conditions or remedies for mitigating negative impacts on privacy and other freedoms, may be separate to and independent from, or integrated into, the analysis carried out by competition authorities during their assessment under competition law". ${ }^{67}$

The EC intentions to analyse the effects of further concentration of commercially sensitive data about customers' personal data in the context of its investigation have been strengthened with the proposed acquisition of Shazam by Apple. Following the takeover, the EC is concerned that Apple would obtain access to commercially sensitive data about customers of its competitors for the provision of music streaming services. Access to such data could allow Apple to directly target its competitors' customers and encourage them to switch to Apple Music. ${ }^{68}$

The EDPB considers it "essential to assess longer-term implications for the protection of economic, data protection and consumer rights whenever a significant merger is proposed, particularly in technology sectors of the economy". ${ }^{69}$

As pointed out by the Max Planck Institute for Innovation and Competition in its Position Statement on the EC's Public consultation on Building the European Data Economy, cases in which private actors seek access to the data of other actors only for the purpose of strengthening

\footnotetext{
${ }^{67}$ EDPB, "Statement of the EDPB on the data protection impacts of economic concentration", 2018. Accessed December 26, 2018. https://edpb.europa.eu/sites/edpb/files/files/file1/edpb_statement_economic_concentration_en.pdf.

68 "Mergers: Commission opens in depth investigation into Apple's proposed acquisition of Shazam", 2018, under "Press Release Database", Press-release_IP-18-3505. Accessed December 26, 2018. http://europa.eu/rapid/press-release_IP-18-3505_en.htm.

69 "Statement of the EDPB on the data protection impacts of economic concentration".
} 
their own decision making is a very complex issue that constitutes the original area of competition policy. However, considering the introduction of a data access right for the beneficiaries of the use of devices in which sensors are embedded, "access regimes can be conceived provided that these regimes are targeted at an identifiable market failure and that they will enhance competition". ${ }^{70}$

One must observe the challenges as well as the difficulties to enforce competition law in each case since these problems are now becoming widespread features of digital markets. Drex ${ }^{71}$ strongly argues in favour of taking additional legislative action outside the realm of competition law, yet such legislation should be competition-oriented.

Digital markets are often very dynamic and characterised by high levels of innovation and, at the same time, highly concentrated by a few big players. Data, or "Big Data", can be of great importance and reveal a central task for competition authorities in the digital economy which is to "keep markets open vis-à-vis powerful or dominant companies to ensure that innovative newcomers and smaller competitors have a chance to succeed". ${ }^{72}$ Explaining the new task of the Bundeskartellamt in consumer protection which complements the possibilities of investigating the digital economy, Mundt ${ }^{73}$ says that to make consumer protection even more effective it would make sense for the competition authority to also obtain enforcement powers in this area. To protect competition and consumers, the German competition authority will use all its efforts to keep pace with the digital economy.

If the competition authority is faced with a situation in which either a competitive problem affects privacy or a matter of privacy interferes with free competition, it must issue a decision in the field of privacy. In these situations, the competition authority often ends up acting as a regulator, but always focused on competition issues.

\footnotetext{
${ }^{70} \mathrm{~J}$. Drexl, et al., Position Statement of the Max Planck Institute for Innovation and Competition of 26 April 2017 on the European Commission's "Public Consultation on Building the European Data Economy", 13.

${ }^{71}$ J. Drexl, Data Access and Control in the Era of Connected Devices Study on Behalf of the European Consumer Organisation. Brussels: BEUC, 2018.

${ }^{72}$ Andreas Mundt, "Sixty years and still exciting: The Bundeskartellamt in the digital era", Journal of Antitrust Enforcement 6, no. 1 (2018). https://academic.oup.com/antitrust/article/6/1/1/4904570.

${ }^{73}$ Mundt, "Sixty years and still exciting", 1-4.
} 


\subsection{Could the procedures in Germany and Italy had been avoided?}

While analysing $21^{\text {st }}$ century capitalism, The Economist ${ }^{74}$ comprehended that a revolution is indeed needed to release competition and force down the unusually high profits of today to ensure that innovation can thrive tomorrow. In the spotlight of these new capitalism companies we can find (mainly) Facebook and Google, which provide popular services at no cost to consumers but subtly push up the costs of other companies through their grip on advertising.

Facebook, for instance, distorts competition by using the mountains of data it collects on users to favour certain partners. It gives them special access to its platform and punish rivals perceived as threats by cutting off their access. Disclosed documents by a British parliamentary committee that is investigating online misinformation show "top executives as they worked to cement Facebook's position as the world's dominant social network". ${ }^{75}$

For sure, competition authorities have a central role to play, especially when fighting against market power. The Economist ${ }^{76}$ pointed out three ways to combat market power. One, data and intellectual property regimes should be used to booster innovation instead of protecting incumbents. Two, governments should remove barriers to entry such as non-compete clauses, occupational licensing requirements and complex and needless regulations. Three, competition laws must be made to fit the $21^{\text {st }}$ century. Regulators need to pay attention to the overall competitive health of markets and to returns on capital. Regulators should have enough powers to investigate markets that are becoming dysfunctional. "Big tech firms should find it much harder to neutralise potential long-term rivals, as Facebook did when it acquired Instagram in 2012 and WhatsApp in $2014 " .77$

A question that always challenges competition authorities is whether to intervene in the dynamic digital markets. In Germany, the Bundeskartellamt conducted an abuse proceeding against Facebook for

\footnotetext{
74 "The next capitalist revolution". The Economist, November 15, 2018. https://www.economist. com/leaders/2018/11/15/the-next-capitalist-revolution?cidl=cust/ednew/n/bl/n/2018/11/15n/ owned/n/n/nwl/n/n/LA/167098/n.

75 "Facebook used people's data to favor certain partners and punish rivals, documents show". The NY Times, December 05, 2018. https://www.nytimes.com/2018/12/05/technology/facebookdocuments-uk-parliament.html.

76 "The next capitalist revolution". The Economist.

77 "The next capitalist revolution". The Economist.
} 
holding a dominant position on the market for social networks and abusing this position by imposing unfair business conditions. Facebook hinges the use of its social network on its permission to limitlessly collect all kinds of data from third sources and match it with the user's Facebook account. This not only applies to data collected by services owned by Facebook, such as WhatsApp, but also to data collected by websites or apps of other operators that Facebook can access. The proceeding does not concern the collection and use of data on the Facebook network itself. Having such market dominance, Facebook's users have no appropriate alternative. The extent and form of data collection violate mandatory European data protection principles. Mundt ${ }^{78}$ observes that "the case work of competition authorities shows that competition law is generally flexible enough to deal with the new issues of digital markets. Nonetheless, we need to think about how to refine and sharpen our tool box".

In Italy, in May 2017, the AGCM considered WhatsApp guilty of having forced its users to share their personal data with Facebook. Pitruzzella observed that "the extent to which big data is the source of competitive advantage and a barrier to entry is not a matter of theory, but an empirical question that has to be addressed with regard to individual markets and specific circumstances" ${ }^{79}$

Since the case was declared by the EC compatible with the internal market and with the EEA Agreement, some investigations were opened by competition authorities. The already mentioned investigations in Germany and Italy somehow confirm that the EU decision on the Facebook/WhatsApp deal offers some dubious thoughts about how precisely it was taken.

It is important to observe that the EC considered that any privacy-related concerns from the increased concentration of data within the control of Facebook because of the deal with WhatsApp would be the scope of EU data protection rules and not a matter of EU competition law rules.

In concluding that the increased concentration of data within the control of Facebook was not a problem for competitive analysis, but rather of EU data protection rules, the EC exempted itself from analysing the effects on competition arising from such concentration. And, by failing to address the issue, the EC failed to prevent competition issues arising from any privacy-related concerns related to the increased concentration of data

\footnotetext{
${ }^{78}$ Mundt, "Sixty years and still exciting", 1-4.

${ }^{79}$ G. Pitruzzella, Big Data, Competition and Privacy, 19.
} 
affecting consumer law and data protection. Both in Germany and Italy, procedures against Facebook/WhatsApp could have been avoided if the EC had attempted to deal with the competitive bias of data concentration.

\section{Conclusion}

The digital economy provides great strides for mankind, especially with the use of Big Data. More specifically in the competition field, Big Data is an important competitive advantage for those companies who own it and can, consequently, extract the best results from its use.

Due to the relevance of Big Data as a competitive advantage, several acquisitions have occurred and are occurring in the digital markets, probably focusing on the concentration of Big Data.

This new reality has fostered an issue that competition authorities are still learning how to deal with and apply in the respective cases. The acquisition of WhatsApp by Facebook is an example of the need for competition authorities to be aware of this new reality and to find the appropriate tools to address the existing and emerging peculiarities and interfaces.

The EU decision on the Facebook/WhatsApp case could have been different if it had considered the cycles of the BDRM - capture, storage and analysis. Furthermore, the decision could have been different if WhatsApp had been considered a player to capture personal data which could reinforce Facebook's performance/dominance in online advertisement. The decision could also have been different if the acquisition of WhatsApp itself were understood as an exclusion of a competitor of the market.

If the competition authority is faced with a situation in which a competitive problem affects privacy or if a privacy issue restricts free competition, it must rule a decision even if it interferes with the field of privacy. In these situations, the competition authority ends up acting as a regulator focused on competition.

Preventing competition issues arising from any privacy-related concerns from the increased concentration of data that can affect consumer law and data protection is a duty of competition authorities. If the EC had attempted to deal with the competitive bias of data concentration, both in Germany and Italy, procedures against Facebook/WhatsApp could have been avoided. 


\section{Bibliography}

Agnellutti, C. Big Data: An Exploration of Opportunities, Values and Privacy Issues. New York: Nova Science Pub Inc., 2014.

Autorità Garante della Concorrenza e del Mercato. "PS11112 - Uso dei dati degli utenti a fini commerciali: sanzioni per 10 milioni di euro a Facebook", 2018, datAllegatinews/PS11112. Accessed December 17, 2018. http://www.agcm.it/dotcmsdoc/allegatinews/PS11112_scorr_sanz.pdf.

Autorité de la Concurrence and Bundeskartellamt. Competition Law and Data. May, 2016, 3. http://www.bundeskartellamt.de/SharedDocs/Publikation/DE/Berichte/ Big\%20Data\%20Papier.pdf?__blob=publicationFile\&v=2.

Bagnoli, V. “Competition for the effectiveness of big data benefits”. International Review of Intellectual Property and Competition Law 46, no. 6 (2015).

Bagnoli, V. “The big data relevant market”. Concorrenza e Mercato 23 (2016), special number Big Data e Concorrenza.

"Big data: Interim report in the context of the joint inquiry on 'Big data' launched by the AGCOM deliberation No. 217/17 / CONS17”. 2018. Accessed November 27. 2018. https://www.agcom.it/documents/10179/10875949/Allegato+4-9-2018/f9befcb14706-4daa-ad38-c0d767add5fd?version=1.0, III.

"Bundeskartellamt initiates proceeding against Facebook on suspicion of having abused its market power by infringing data protection rules", 2016, Pressemitteilungen/2016/02_03_2016. Accessed December 26, 2018. http://www.bundeskartellamt.de/SharedDocs/Meldung/EN/Pressemitteilungen/2016/02_03_2016_ Facebook.html?nn=3599398.

"Bundeskartellamt prohibits Facebook from combining user data from different sources", 2019. in https://www.bundeskartellamt.de/SharedDocs/Publikation/EN/ Pressemitteilungen/2019/07_02_2019_Facebook.pdf?_blob=publicationFile\&v=2,

Chen, M., Mao, S., Zhang, Y. and Leung, V. C. M. Big Data: Related Technologies, Challenges and Future Prospects. London: Springer, 2014.

Commission decision of 6 October 2014, pursuant to Article 6(1)(b) of Council Regulation No. 139/2004, Case no. COMP/M.7217, Facebook/WhatsApp. http://ec.europa.eu/ competition/mergers/cases/decisions/m7217_20141003_20310_3962132_EN.pdf.

Craig, T., Ludloff, M. E. Privacy and Big Data. Sebastopol, CA: O’Reilly, 2011.

Cumbley, R., Church, P. “Is big data creepy?”. Computer Law \& Security Review 29, 2013.

Drexl, J. Data Access and Control in the Era of Connected Devices Study on Behalf of the European Consumer Organisation. Brussels: BEUC, 2018.

Drexl, J., et al. Position Statement of the Max Planck Institute for Innovation and Competition of 26 April 2017 on the European Commission's "Public consultation on Building the European Data Economy". 
European Data Protection Board. "Statement of the EDPB on the data protection impacts of economic concentration”, 2018. Accessed December 26, 2018. https://edpb.europa. eu/sites/edpb/files/files/file1/edpb_statement_economic_concentration_en.pdf.

European Data Protection Supervisor. "Preliminary Opinion of the European Data Protection Supervisor. Privacy and Competitiveness in the Age of Big Data. The interplay between data protection, competition law and consumer protection in the Digital Economy”, 2014. Accessed December 26, 2018. https://edps.europa.eu/sites/edp/files/ publication/14-03-26_competitition_law_big_data_en.pdf.

European Data Protection Supervisor. "Report of EDPS workshop on privacy, consumers, competition and big data", 2014. Accessed December 26, 2018. https://edps. europa.eu/data-protection/our-work/publications/reports/report-edps-workshop -privacy-consumers-competition-and_en.

"Facebook fined 10 million Euros by the ICA for unfair commercial practices for using its subscribers' data for commercial purposes", 2018, Press-releases/2018/12. Accessed December 17, 2018. http://en.agcm.it/en/media/press-releases/2018/12/Facebookfined-10-million-Euros-by-the-ICA-for-unfair-commercial-practices-for-using-itssubscribers\%E2\%80\%99-data-for-commercial-purposes.

"Facebook used people's data to favor certain partners and punish rivals, documents show." The NY Times, December 05, 2018. https://www.nytimes.com/2018/12/05/ technology/facebook-documents-uk-parliament.html.

Fishleigh, J. A Non-Technical Journey into the World of Big Data: An Introduction. Cambridge: Legal Information Management, 2014.

Frank, J. S. "Competition concerns in multi-sided markets in mobile communication". In G. Surblyté. Competition on the Internet. MPI Studies on Intellectual Property and Competition Law, vol. 23. Berlin: Springer, 2015.

Graef, I. "Market definition and market power in data: The case of online platforms". World Competition 38, no. 4 (2015): 473-506.

"Mergers: Commission approves acquisition of WhatsApp by Facebook", 2014, under "Press Release Database”, Press-release_IP-14-1088. Accessed June 01, 2018. http:// europa.eu/rapid/press-release_IP-14-1088_en.htm.

"Mergers: Commission fines Facebook $€ 110$ million for providing misleading information about WhatApp takeover", 2017, under "Press Release Database", Press-release_IP-17-1369. Accessed November 11, 2018. http://europa.eu/rapid/ press-release_IP-17-1369_en.htm.

"Mergers: Commission opens in depth investigation into Apple's proposed acquisition of Shazam", 2018, under "Press Release Database”, Press-release_IP-18-3505. Accessed December 26, 2018. http://europa.eu/rapid/press-release_IP-18-3505_en.htm. 
Mayer-Schönberger, V., Ramge, T. Reinventing Capitalism in the Age of Big Data. New York: Basic Books, 2018.

McKinsey Global Institute. "Big Data: The Next Frontier for Innovation, Competition, and Productivity, May 2011, Report", 2011, https://www.mckinsey.com/businessfunctions/digital-mckinsey/our-insights/big-data-the-next-frontier-for-innovation.

Moon, H. and Cho, H.S. "Big data and policy design for data sovereignty: A case study on copyright and CCL in South Korea". Social Com, 2013.

Mundt, Andreas. "Sixty years and still exciting: The Bundeskartellamt in the digital era". Journal of Antitrust Enforcement 6, no. 1 (2018). https:/academic.oup.com/antitrust/ article/6/1/1/4904570.

OECD. Data-Driven Innovation: Big Data for Growth and Well-Being. Paris: OECD Publishing, 2015. http://dx.doi.org/10.1787/9789264229358-en.

OECD. The Digital Economy, 2012.

Pitruzzella, G. "Big data, competition and privacy: A look from the antitrust perspective”. Concorrenza e Mercato 23 (2016), special edition Big Data e Concorrenza.

"Preliminary assessment in Facebook proceeding: Facebook's collection and use of data from third-praty sources is abusive", 2017, Pressemitteilungen/2017/19_12_2017. Accessed July 14, 2018. https://www.bundeskartellamt.de/SharedDocs/Meldung/EN/ Pressemitteilungen/2017/19_12_2017_Facebook.html?nn=3591568.

Shafer, T. "The 42 Vs of big data and data science". Elder Research - Data Science and Predictive Analytics. https://www.elderresearch.com/company/blog/42-v-of-big-data.

Statement of the EDPB on the data protection impacts of economic concentration. Accessed December 26, 2018. https://edpb.europa.eu/sites/edpb/files/files/file1/ edpb_statement_economic_concentration_en.pdf.

“Tech's frightful five: They've got us”. The NY Times, May 30, 2017. https://www.nytimes. com/2017/05/10/technology/techs-frightful-five-theyve-got-us.html?_r=0.

"The next capitalist revolution". The Economist, November 15, 2018. https://www.economist.com/leaders/2018/11/15/the-next-capitalist-revolution?cidl=cust/ednew/n/ $\mathrm{bl} / \mathrm{n} / 2018 / 11 / 15 \mathrm{n} / \mathrm{owned} / \mathrm{n} / \mathrm{n} / \mathrm{nwl} / \mathrm{n} / \mathrm{n} / \mathrm{LA} / 167098 / \mathrm{n}$.

The White House: Executive Office of the President. Big Data: Seizing Opportunities, Preserving Values, 2014.

“The world's most valuable resource is no longer oil, but data", The Economist, May 6, 2017. Accessed May 21, 2017. http://www.economist.com/news/leaders/21721656 -data-economy-demands-new-approach-antitrust-rules-worlds-most-valuableresource.

Vezzoso, S. "Internet competition and e-books: Challenging the competition policy acquis?" In G. Surblyté. Competition on the Internet. MPI Studies on Intellectual Property and Competition Law, vol. 23. Berlin: Springer, 2015. 
Vezzoso, S. "Pro-competitive regulation of personal data protection in the EU". In J. Drexl; V. Bagnoli. State-Initiated Restraints of Competition. Cheltenham: Edward Elgard, 2015.

"WhatsApp fined for 3 million euro for having forced its users to share their personal data with Facebook", 2017, Press-releases/2380. Accessed June 06, 2017. http://www. agcm.it/en/newsroom/press-releases/2380-WhatsApp-fined-for-3-million-euro-forhaving-forced-its-users-to-share-their-personal-data-with-facebook.html. 